\title{
Welcome to the Second Volume of Trends in Renewable Energy
}

With the help of all authors and enthusiastic editorial team members, the Trends in Renewable Energy (TRE) completed the publication of first volume. We deeply appreciate your support, and are looking forward to continuously working with all colleagues around the world.

We also would like to thank you for all nominations for the 2015 TRE Author of the Year Award. The award of this year goes to Dr. Athanasios G. Lazaropoulos at the National Technical University of Athens, Greece. Dr. Lazaropoulos gave our journal tremendous supports during 2015, and his papers often show high quality. Next nomination period will be this December, and categories will include the Author of the Year, the Paper of the Year, and the Editor of the Year.

Low petroleum price did impact the interest of renewable energy technologies last year. But considering advantages of these novel energy technologies along with the benefits of environmental and economic factors, we believe that renewable energy is still one of fastest developing areas. In 2015, governments showed their visions on the development of renewable energy technologies. US Department of Energy granted numerous projects related to clean energy, energy efficacy, energy conservation, and renewable energy technologies. In December 2015, USDA-EPA-DOE released the Biogas Opportunities Roadmap Progress Report, in which challenges and opportunities for the robust biogas industry are outlined. We are expecting that this growing trend of renewable energy will be extended through 2016 and 2017.

We will continue the TRE's mission to publish quality reviews, original research, and application-oriented papers, providing a communication platform that is run exclusively by scientists working in the renewable energy field. Papers are invited on any individual topic related to renewable energy or those that are interdisciplinary. The article processing charge (APC), i.e. the publication fee, is fully waived for papers published during 2016.

Bo Zhang

Editor in Chief

January 1, 2016 